This is the author's final, peer-reviewed manuscript as accepted for publication. The publisher-formatted version may be available through the publisher's web site or your institution's library.

\title{
Teaching old dogs new tricks: the effectiveness of community-based social marketing on energy conservation for sustainable university campuses
}

Jennifer Aronoff, Ben Champion, Casey Lauer, and Anil Pahwa

\section{How to cite this manuscript}

If you make reference to this version of the manuscript, use the following information:

Aronoff, J., Champion, B., Lauer, C., \& Pahwa, A. (2013). Teaching old dogs new tricks: The effectiveness of community-based social marketing on energy conservation for sustainable university campuses. Retrieved from http://krex.ksu.edu

\section{Published Version Information}

Citation: Aronoff, J., Champion, B., Lauer, C., \& Pahwa, A. (2013). Teaching old dogs new tricks: The effectiveness of community-based social marketing on energy conservation for sustainable university campuses. IEEE Power and Energy Magazine, 11(1), 30-38.

Copyright: (O2013 IEEE

Digital Object Identifier (DOI): doi:10.1109/MPE.2012.2225234

Publisher's Link: http://ieeexplore.ieee.org/xpl/articleDetails.jsp?arnumber=6400336

This item was retrieved from the K-State Research Exchange (K-REx), the institutional repository of Kansas State University. K-REx is available at http://krex.ksu.edu 


\section{Teaching Old Dogs New Tricks}

The Effectiveness of Community-Based Social Marketing on Energy Conservation for Sustainable University Campuses

By Jennifer Aronoff, Ben Champion, Casey Lauer, and Anil Pahwa 
As global population continues to grow and concurrent energy use continues to climb, it is crucial for college campuses to greatly reduce their overall demand for energy. Higher education has continually offered creative and innovative solutions for problems faced by society as a whole. Over the past several years, numerous colleges and universities have started to recognize their responsibility for reducing the negative impact on the surrounding environment. While technical solutions to energy conservation are still essential, energy reduction can be achieved more rapidly through behavior change. However, the question still remains: how can we get people to change their preset unsustainable habits?

Community-Based Social Marketing (CBSM) developed by Dr. Doug McKenzie-Mohr is a theory that identifies and addresses barriers that impede individuals from converting attitudes and concern for the environment into action. The principal barriers that hinder sustainable actions are:

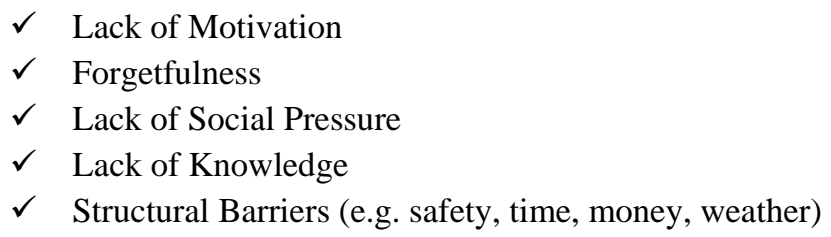

Identifying motivations and determining perspectives on energy efficiency can assist in developing strategies to eliminate these barriers so that this concern can be converted into meaningful action. These strategies will enable higher educational institutions to create truly sustainable communities. Universities will be unable to conserve energy the way they need to without the creation of an effective management plan that eliminates these barriers while also empowering and motivating building users and managers.

A CBSM study was conducted at Kansas State University to determine potential strategies to decrease energy consumption on these campuses. The study was supported by a National Science Foundation Research Experience for Undergraduates (REU) project "Earth, Wind, and Fire: Sustainable Energy for the $21^{\text {st }}$ Century". The ultimate goal of this research is to establish an effective campaign to make Kansas State University a more sustainable community, while also ensuring that the needs and concerns of individuals, specifically laboratory scientists, on campus are addressed. This approach to sustainability has the capability of motivating and empowering building users and managers to not only make Kansas State University's campus more sustainable, but also to eventually stretch beyond the boundaries of the university.

\section{Why Community-Based Social Marketing?}

Residential and commercial buildings account for almost two-thirds of the total energy consumption in the United States. On college campuses, energy use occurs in either residential or academic buildings. Most campus-based energy conservation programs utilized in the past were based solely on informational campaigns along with the installation of energy efficient systems. As will be discussed, research has indicated that attempting to bring about behavior changes based exclusively on increasing public knowledge about certain environmental concerns rarely produces substantial effect upon increasing sustainable and desirable behavior. Dr. Scott Geller has shown that there was little correlation between one's attitudes and the resulting behavior. He determined in one study that, "although providing information and promoting awareness of a problem are often important components to an intervention, information alone is seldom sufficient to change behavior." While educating or installing energy efficient systems throughout campuses requires less human thought or work to obtain energy use goals, substantial and sustainable reduced energy use can only be reached through behavior change, which must become the cornerstone of creating sustainable campuses.

CBSM provides an alternative pragmatic approach to producing meaningful behavior change and enables the creation of interconnectedness between individuals and the environment by identifying potential barriers to behavior change and developing strategies to eliminate them. These barriers, whether internal or external, hinder commitment to an array of sustainable behavior. A CBSM template allows for 
campuses to tailor personal energy reduction needs to their specific environment based on a five-step process:

1. Selecting a specific behavior to promote;

2. Identifying potential barriers and benefits to that activity;

3. Developing strategies to conquer these barriers;

4. Piloting of the strategy initially into a small portion of the community; and

5. Implementing and evaluating on a broad-scale implementation the effects of the program.

Implementing a similar campaign will promote positive behavior change throughout campus communities in order to effectively develop practices that will create a sustainable campus environment.

\section{Review of Issues Impacting Individual Change}

\section{Energy Invisibility}

One of the biggest barriers to behavior change with respect to energy conservation is the "invisibility" of

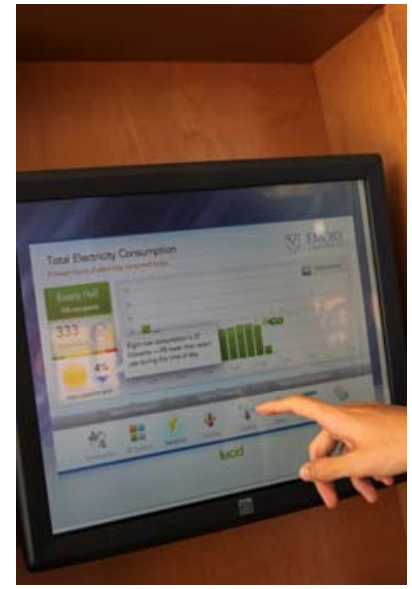

Figure 1. An energy monitor in a residence hall at Emory University (Courtesy: Tina Chang- Emory University ) enegy. With the advancement of technology over the last century, energy flows have become almost undetectable to energy consumers. This, in combination with our views of energy as not only a necessity, but also a commodity, has hindered our ability to learn how to use energy more wisely and ultimately become less wasteful. Inability to see one's energy use eliminates the opportunity to assess daily behavior and its effect on energy efficiency to ultimately learn from it. Providing feedback through different means, such as an energy consumption monitor shown in Figure 1 allows people to become more directly aware of their own consumption even if they are unable to immediately see the environmental and/or economic consequences of this energy use. The creation of a tangible link between environmental and economic impacts is crucial in producing substantial behavior change related to energy conservation.

\section{Feedback Systems}

One deficiency of many prior information-based campaigns is that they failed to create a concrete link between daily needs and the costs associated with choices made by campus communities on the surrounding environment. Since many members of a campus community (including faculty and staff) do not have direct economic incentives to reduce energy consumption, feedback has the potential to create motivation to act, at least morally or ethically. Multiple studies have demonstrated that feedback relative to energy consumption makes the consequences of the behavior salient, therefore increasing the likelihood of longer-term changes. In all of these cases, feedback served as a great instructional tool to allow education through experimentation. With readily accessible and easily interpretable data at their fingertips, individuals became empowered and motivated to conserve energy. However, after feedback ended consumptive behavior increased. One question that many campuses face is one in terms of a cost-benefit analysis. That is, does the total expenditure for monitoring outweigh how much can be potentially saved from reduction of energy use based on feedback received? Several institutions have shown that it is possible to create a relatively low cost feedback system that can motivate individuals on college campuses to reduce their resource use. However, since feedback is not always effective in promoting more 
permanent behavior change, it must be combined with other tools such as incentives, in order to increase permanency.

\section{Incentives}

The use of both extrinsic and intrinsic awards to positively promote and encourage individuals to repeat certain behaviors has proven very effective in promoting and encouraging sustainable action. When individuals discover they will gain something, either tangible or intangible by participating in the behavior advertised, they are motivated to engage in the desired behavior. For instance, in a survey performed at Michigan University, $72 \%$ of the faculty admitted to the fact that they would be more likely to conserve energy if the money they saved went directly towards their department. With respect to tangible rewards, it is important to design incentives large enough to draw people into the behavior, but at the same time, not big enough to have diminishing returns. It is also important to contemplate long-term behavior change in relation to motivational tools. Although immediate rewards are very powerful and encourage more rapid behavior change, indirect rewards have been shown to be more effective in promoting long-term behavioral change in a target audience. Many previous studies revealed that reductions in consumption from extrinsic motivations diminished after those incentives were removed. In order to increase the durability of this approach, the intervention period would need to span over several months to several years in order to increase the effectiveness of behavior change and keep behavior from returning to baseline levels. Both monetary incentives and intangible rewards are very successful in creating sustainable behavior change across college campuses, especially when previous participation rates are low.

An intriguing aspect of increasing sustainable behaviors is the effect of group incentives on transforming individual behavior. Combining incentives with commitments can transform extrinsic motivations into intrinsic ones, creating a more durable behavior change. Strong social motivation to reinforce behaviors can be robust. Several competitions have been implemented in recent years across

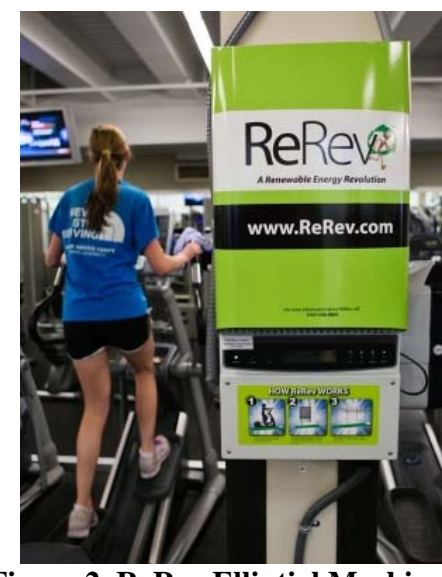

Figure 2. ReRev Elliptial Machine at Furman University

(http://www.aikenstandard.com/story/ m1032-BC-SC-MusclePower-2ndLdWritethru-11-27-1036--3607739) college campuses to see which residential buildings can achieve the greatest reductions. These close-knit "communities" of individuals have created substantial decreases in energy use. One of the most effective competitions set up was one between the University of Oregon and Oregon State University. These institutions competed to see who could "generate" the most energy from work out machines from ReRev shown in Figure 2 that helps convert kinetic energy into electricity. The intense rivalry between the schools and the school spirit among each individual university lead to the generating over 24,000 watt hours combined in a week. While this is an accomplishment, the amount of energy actually produced given the hundreds of people participating was minimal. However, not only did this competition draw huge crowds to participate, it also demonstrated that change in behavior is necessary in order to create a sustainable campus. While installation of energy efficient technologies can have some effect, effective use of incentives leads to the creation of more sustainable behavior among individuals. As with feedback tools, though, durability can be low.

\section{Social Norms and Commitment}

As creatures of habit, many individuals maintain routines and often appear to be change adverse. An important, but often overlooked, aspect of behavior change in relation to energy conservation is individual relationships and the impacts of those relationships on individual behavior. Many psychologists agree that humans conform to the actions and beliefs of surrounding peers. A prominent psychologist focusing on the 
psychology of persuasion, Dr. Robert Cialdini, proposes that people tend to do what is socially "approved" and "popular." Not only do we conform to normative behavior (what behaviors are normally engaged in by peers), but also to injunctive norms (what behavior is viewed by others as approved and disapproved). Injunctive and normative norms have such an influence over our daily lives that social norm messages (such as fliers) are simply not sufficient to induce change among individuals who interact with each other daily.

A major element of conformity, gaining social approval, is a very conscious and deliberate attempt by individuals to build rewarding relationships and gain approval, thereby enhancing individual selfesteem. Although conformity in large measure is due to "conscious" decisions, in fact, much of our conformity operates completely outside an individual's conscious awareness. These conscious and unconscious mechanisms of mimicry have proven to be very effective in showing the impact of social norms on individuals engaging in sustainable behavior. Seeing other individuals supporting sustainable initiatives make others more likely to alter their personal behaviors.

Moral norms, which are activated when people become aware of negative interpersonal consequences of actions, can lead to individuals accepting personal responsibility for consequences of their action. This internal manipulation and conflict leading to feelings of guilt is a powerful motivational tool, often leading to changes in behavior. By creating these intrinsic motivations, individuals are more likely to engage in more meaningful behavior and have the ability to

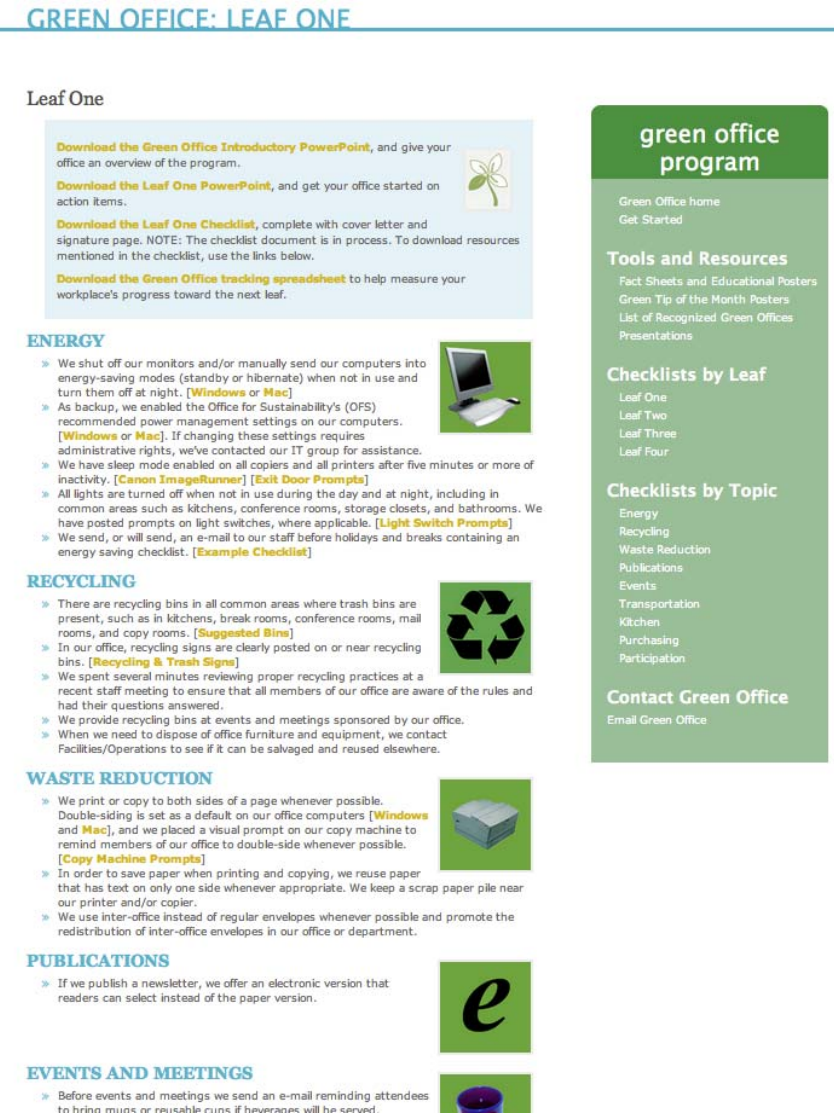
apply the knowledge to other situations. Comparison of internalized self-expectations to others' actions activates these personal moral norms. Although this sense of remorse can be an extremely effective tool for behavior change, it also has the power to evoke a "go against the grain” mentality.

Often moral norms become activated because of our commitments to remain consistent. People like to behave consistently in order to create a more enduring way of how individuals view themselves. Group commitments are especially effective because they create a commitment to action on an individual level that people begin to view as not only an optional contribution, but also necessary. In Harvard University's Green Leaf Office Program (Figure 3), both social norms and commitments play paramount roles in the success of transforming behavior in academic

Figure 3. Part of Harvard's Green Leaf office program (http://www.green.harvard.edu/green-office/).

buildings. The Green Leaf program is a four-tier sustainability certification process in nine categories (including energy, participation, and meetings). The program, which is based on CBSM, taps into both community and social norms to encourage personal behaviors. Their biggest success with the program has 
come from commitment. Not only do they ask for group commitment, which has proven to be a strong motivational factor in previous literature, but they ask for written commitment as well. At least $75 \%$ of faculty and staff must affirm they have participated in the current green initiatives. The group incentive created a greater responsibility and likeliness to act. When individuals create this powerful motive force, they are more likely to continue the behavior even after the intervention has terminated.

\section{Convenience and Prompts}

One of the most significant barriers to effective behavior change is the lack of convenience for the necessary action(s). Prior studies have shown that behaviors, coupled with inconvenience, have low participation levels. Important choices must be made between efficiency behaviors and more permanent interventions. A big push at several universities across the country has been to adopt "efficiency behaviors:" one-time behaviors that can reap repeated benefits from continued use (such as installing lighting sensors). The EPA "Energy Star" program encourages buying energy efficient appliances for dorm rooms, laboratories, and offices. There have been many success stories throughout the United States with interventions such as installing CFLs (compact fluorescent lights). While these one-time actions are helpful, greater energy reduction will be the product of behavior change in individuals. Therefore, it is essential to implement more permanent interventions that will increase the compliance of sustainable behaviors.

As noted above, if it is inconvenient to perform or maintain certain behaviors, individuals often forget to engage in that sustainable behavior. The use of visual prompts has proven to be extremely effective in changing behavior when paired with other methods, such as feedback, social norms and commitment. Prompts remind individuals of desirable target behaviors. Simple, specific, and direct slogans serve as a motivational tool for countless individuals on campuses. Several universities across the United States have begun to realize considerable successes with reducing energy in research labs in academic buildings. Although they not occupy a large percentage of campus buildings, labs tend to use close to one-third of the total energy consumption on campus. A simple prompt that Emory University, Harvard University, MIT, UC Davis, and others have implemented is a sash height sticker placed directly next to the fume

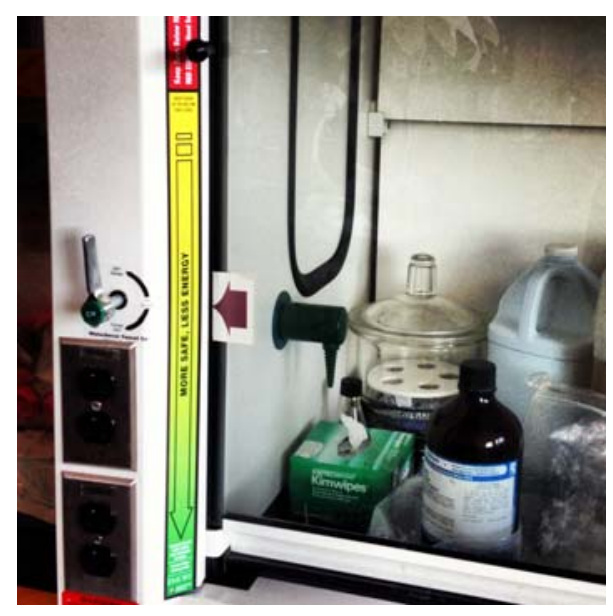

Figure 4. Fume hood sash sticker at Emory University displaying acceptable levels for sash heights (sticker has an arrow pointing toward the green (bottom of the fume hood) saying "More Safe, Less Energy.") hood. Because prompts are a relatively low cost undertaking, they have the potential to change behavior resulting in large energy reductions without breaking the bank. Prompts also add an element of persistence, which serves to increase compliance with energy conservation behaviors.

\section{Methodology: CBSM Energy Perspectives Survey at Kansas State University}

Potential energy-related behavior change on college campuses was analyzed through a project focused on energy conservation opportunities in research laboratories at Kansas State University during the summer of 2011. The CBSM framework along with the process displayed in Figure 5 was used as to evaluate strategies for generating energy conservation behavior change in university laboratory spaces. 
Department heads in the College of Engineering and other natural science department heads were contacted to perform in-person interviews. If department heads could not be interviewed, graduate students in their respective laboratories were. Overall 19 individuals were interviewed. Of the 19, undergraduate students comprised 3; graduate students 4; staff 2; and faculty members and professors 10. All persons interviewed work or study in the natural sciences, with almost $75 \%$ of those interviewed affiliated with engineering science departments. Over half (57.89\%) of the subjects used laboratories, classrooms, and

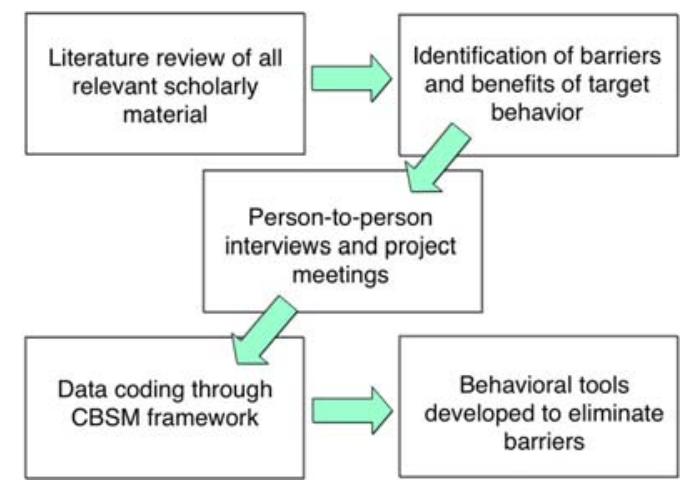

Figure 5. Process and methodology for data analysis within the CBSM framework offices in the three buildings comprising the engineering complex. All of them have more than one computer. Only 6 of the 19 respondents power down computers and printers at night. Other didn't do that for various reasons as shown in Figure 6. Participants were informed of the project's goal to determine motivations of the different energy users on campus and analyze perspectives on energy efficiency on campus to create an effective campaign to make Kansas State University a more sustainable community. The interviews conducted were semi-structured, so they were flexible to discuss issues not originally included in the survey, allowing richer data about barriers to individual energy conservation efforts among interviewees.

Utilizing data coding methodologies (a systematic way in which to condense extensive data sets into smaller analyzable units through the creation of categories and concepts derived from the data), analysis of the interview responses allowed us to identify common barriers with which the laboratory scientist energy users on campus identified within a the five barriers identified in the CBSM framework.

\section{Results: Lessons for Shaping an Energy Conservation Plan at Kansas State University}

The interview responses helped identify several behavioral barriers among the laboratory scientists

\section{Energy Conservation Barriers Faced by KSU Campus Energy Users}

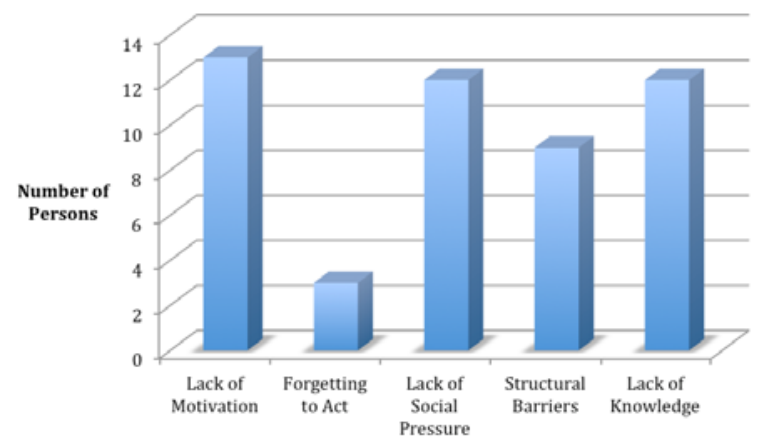
interviewed. Barriers such as lack of knowledge, structural barriers, and lack of motivation all directly contribute to the perpetuation of unsustainable actions as shown in Figure 7. These responses evidence many gaps or disconnects among building users' energy and conservation knowledge. Key phrases and words in the data discovered from SWOT analysis are discussed below in a manner that aligns the responses with relevant and applicable barriers. The analysis of these barriers aided in the first steps to producing a

Figure 7. Responses on conservation barriers 
general theory of behavior change applicable to the lab scientist population and potentially all of a campus community.

\section{Lack of Motivation}

The biggest barrier faced by individuals that became apparent during the person-to-person interviews was a lack of motivation. Without extrinsic or intrinsic motivation, individuals will refrain from participating in sustainable behaviors. Almost all individuals mentioned that there would need to be a "personal benefit versus just helping the environment" in order to motivate themselves to change personal behaviors.

A lack of motivation from these energy users on Kansas State University's campus stems from the absence of any tangible link between their daily, and often unsustainable actions, with the resulting consequences on either the environment or their impact financially. Several subjects demonstrated a willingness to "make their mark on the world," yet concurrently indicating a desire to achieve the "biggest bang for their

\section{Perspectives on Energy Conservation at KSU}

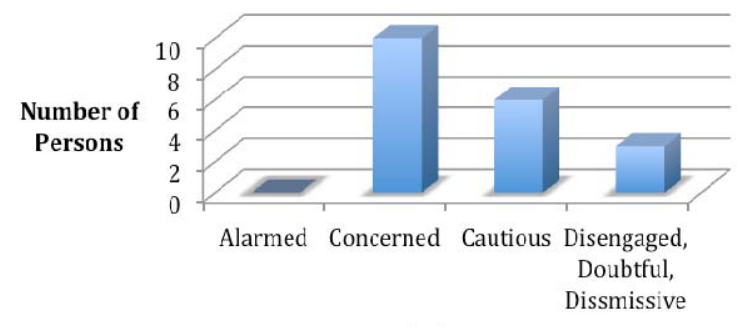

Level of Concern buck" in terms of what behaviors to adopt.

The understanding of how individual actions impact the collective whole forms a critical element of sustainable behavior change. The lack of social pressure and a lack of commitment to a group also detrimentally impact the motivation levels of the interview subjects. One individual succinctly articulated the barrier: "why should they cut back and conserve energy when nobody else is

making an effort?" Will individual small and simple steps, such as turning off lights in unoccupied rooms, actually make a difference? Another individual mentioned how they had "given up" because the larger population either has no time or no motivation to participate in sustainable behaviors as well.

Overall, almost $80 \%$ of the interview subjects agreed with the need to establish energy conservation as a high priority on campus. Each of those individuals also indicated a willingness to meet with representatives from either the Facilities Management Office or the Office of Sustainability to identify ways in which they can participate in sustainable behaviors. Despite that receptivity, some degree of cynicism pervades such responses, since only $50 \%$ of those individuals, while acknowledging the need, described themselves as being truly motivated and believing that it will have some influence over

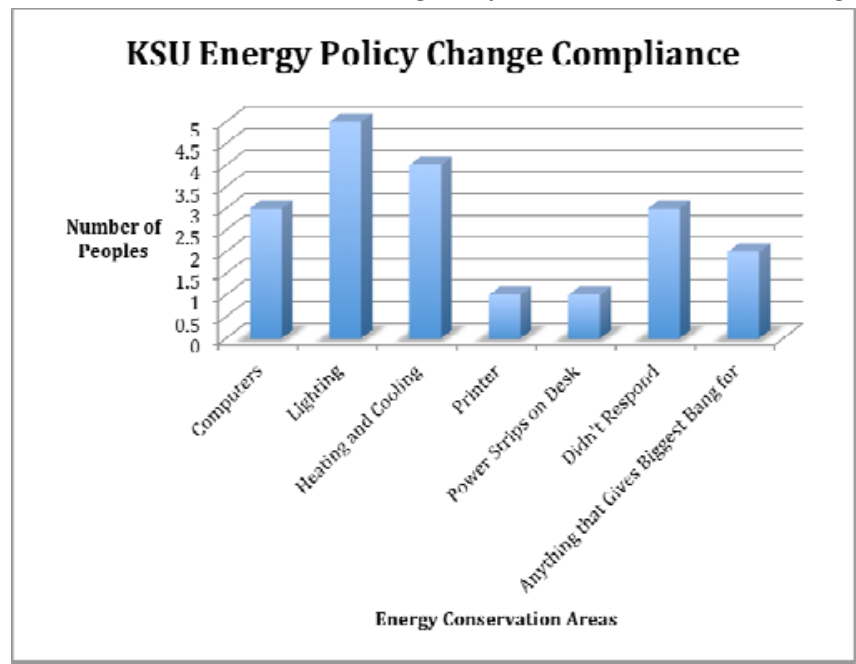
individual behaviors (Figure 8). The subjects who did not label themselves as disengaged, dismissive, or doubtful are willing to comply with changes in computer management, heating/cooling, lighting, etc. if Kansas State University implements policy changes (Figure 9).

When determining who should bear the most responsibility in terms of conserving energy on campus, "individuals" were not given significant prominence. The majority believed that the responsibility for energy conservation must be shouldered by facilities and the administration as shown in 
responses in Figure 10. Why is it that the majority of the scientists were willing to comply with policy changes requiring them to act more sustainably, yet they were quick to place the responsibility of conserving energy on others' shoulders? Such a potential barrier, along with other impediments, must be considered in order to develop conservation strategies that can enjoy some measure of success.

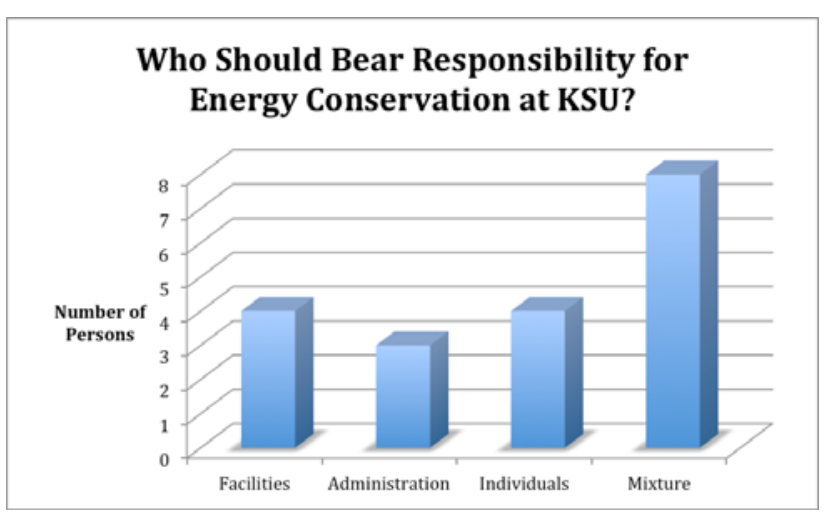

Figure 10. Responsibility for energy conservation

\section{Forgetfulness}

Forgetfulness was only seen as a barrier to participating in sustainable behaviors by $15 \%$ of those interviewed. Yet a particularly poignant comment among the many answers showed that "just talking to you has made me start to think about energy conservation again.” Our culture today has transformed our society into one filled with mundane unsustainable routines and habits. For many people, it is not that they lack a desire to live sustainable lifestyles. Rather, it is from simply forgetting to power down computers at night or turn off the lights when they leave laboratories and offices. Any tendency towards forgetfulness should be incorporated in the design and structuring of the strategies and program to be adopted by Universities.

\section{Lack of Social Pressure}

A lack of understanding among individuals at Kansas State University proves to be a substantial barrier to performing sustainable behaviors. The biggest barrier faced in changing behavior in favor of energy conservation is trying to capture attention and persuade individuals. Vivid and "realistic" facts are what the majority of people interviewed felt that they lack in order to persuade them to change behaviors. The majority of individuals talk about a lack of communication between several disciplines claiming that, "miscommunication and lack of information is the cause." Many of the individuals interviewed were not aware of the energy conservation work currently going on throughout the campus. A few even admitted to not knowing that Kansas State University had a Director of Sustainability, even though the position was established over three years ago.

Several studies have documented the magnitude of effect that social norms have upon individual behavior, yet almost two-thirds (63.16\%) of the surveyed individuals claim that low levels of social pressure keep them from participating in sustainable behaviors. Many expressed how the lack of leadership is one cause for lagging pressure. A number (78.95\%) of the laboratory scientists claim that social pressure needs to come from the administration and facilities. Without this extra departmental pressure and encouragement, individuals will not be motivated to change behaviors.

Like many other academic institutions, descriptive norms dominate the population interviewed at Kansas State University. "Only a select group of people take their own initiative” to try and reduce energy use on campus, while the rest appear "oblivious" to all energy conservation efforts. Individuals are not faced with constant exposure to aid in the thinking process about energy conservation daily. While various individuals possess an "all in this together" mentality, at this point, the majority of individuals in the natural science departments interviewed do not. Some individuals claimed that bringing in University resources to brief departments about specific energy saving measures would demonstrate the priority of the initiative and put pressure on them to participate. If injunctive norms are transformed to ones that disapprove of unsustainable behaviors, greater behavior change can be reached. 


\section{Lack of Knowledge}

One laboratory scientist claimed that they leave their overhead lights on when they leave the room for extended periods of time because they were told that such a practice uses less energy than turning lights on and off frequently. Other scientists are unaware of current building regulations that require a certain portion of common space area to be illuminated at all times. Educating these individuals can potentially lead to increased knowledge of how to more efficiently use lighting in their offices and labs and become more energy conscious.

\section{Structural Barriers}

Structural barriers are external barriers, which hinder our ability to partake in sustainable behaviors. Many structural barriers such as safety, money, time, and weather can serve as inconveniences and become powerful motivators to choose unsustainable daily habits. A major theme that appeared throughout the interviews was that time was a limiting factor. Many of the individuals expressed desires to have someone "hold their hand through the process." They want to spend as little time and effort creating their own solutions for individual laboratory or workspaces. Since research is of considerable importance to Kansas State University and many other universities, the researchers, from undergraduate students to faculty, felt that productivity and safety were far superior priorities to themselves than to take the time to figure out how recommendations for sustainable actions can apply directly to their office and lab spaces. Providing merely three simple suggestions on how to reduce energy use may help to alleviate this feeling.

\section{Conclusions: CBSM and Energy \\ Conservation in the Future}

The data gathered with respect to the various motivations and perspectives on energy efficiency at Kansas State University demonstrates that several barriers need to be addressed in order to perpetuate behavior change in favor of energy conservation among both laboratories and other buildings and areas on college campuses. Lighting, heating and cooling, and computer management were identified as the three areas in which people are most likely to comply with energy conservation policies. Figure 11 shows barriers and tools that can be used to overcome these barriers.

Intrinsic motivations will be an essential ingredient in boosting participation rates among individuals across college campuses. Creation of a group commitment and an increase of social norm

\begin{tabular}{|c|c|}
\hline Barriers & Tools \\
\hline Lack of Motivation & $\begin{array}{c}\text { Commitment, Norms, } \\
\text { Incentives }\end{array}$ \\
\hline Forget to Act & Prompts \\
\hline $\begin{array}{c}\text { Lack of Social } \\
\text { Pressure }\end{array}$ & Norms \\
\hline Lack of Knowledge & $\begin{array}{c}\text { Communication, } \\
\text { Social Diffusion }\end{array}$ \\
\hline Structural Barriers & Convenience \\
\hline
\end{tabular}

Figure 11. Tools that can be used to overcome major barriers impeding sustainable action pressure have the potential to be the most valuable intrinsic incentives within a university's atmosphere. As prominent psychologists, like Cialdini note, individuals conform to both behaviors that are normally engaged in by peers and those behaviors which are viewed as "approved." If the majority of individuals act unsustainably, others tend to conform to those descriptive norms/what is seen as behavior commonly engaged in. In order for these descriptive norms to become outdated, we need "examples to break our current bad habits." If universities can create a culture where sustainable behaviors are the norm, then individuals should feel greater pressure to

conform-both consciously and unconsciously through behavioral mimicry. When commitments become involved, not only do individuals strive to behave like surrounding peers, but a feeling of consistency might also arise. Since campus energy users do not pay for electricity, let alone see a utility bill, they lack a tangible connection with energy usage. Often individuals lack either the basic fundamental knowledge of 
the conservation actions in which to participate, or, once identified, how to engage in them. While knowing what activities to perform is important, the lack of knowledge as to how much energy individuals were using personally, or how much even a single appliance consumes.

By analyzing motivations of different energy users and implementing strategies to eliminate these barriers and change attitudes and concern for the environment into action, colleges across the country have the potential to generate significant energy and thus financial savings. While technical challenges are still essential, behavior change will be paramount across college campuses to become truly sustainable.

Analyzing energy perspectives and motivations of energy users on campus is needed to create a successful tailored program in order to create durable sustainable behavior change.

\section{For Further Reading}

Aronson, E. and O'Leary, M. The Relative Effectiveness of Models and Prompts on Energy Conservation: A field Experiment in a Shower Room. Journal of Environmental Systems, 1982, 12, 3, 219-224.

Cialdini, R. B. Crafting Normative Messages to Protect the Environment. Current Directions in Psychological Science, 2003, 12, 105-109.

Geller, E.S. Evaluating Energy Conservation Programs: Is Verbal Report Enough? Journal of Consumer Research, 1981, 8, 331-335.

Hayes, S.C. and Cone, J.D. Reduction of Residential Consumption of Electricity Through Simple Monthly Feedback. Journal of Applied Behavior Analysis, 1981, 14, 81-88.

Marans, R. and Edelstein, J. The Human Dimension of Energy Conservation and Sustainability: A Case Study of the University of Michigan's Energy Conservation Program. International Journal of Sustainability in Higher Education, 2010, 11(1), 6-18.

McKenzie-Mohr, D. Fostering sustainable behavior: An Introduction to Community-Based Social Marketing. Gabriola Island, British Columbia, Canada: New Society, 1999.

\section{Biographies}

Jennifer Aronoff completed B.S. in Environmental Science in May 2012 and is pursuing Master of Public Health in Environmental Health at Emory University.

Ben Champion (Director of Sustainability), Casey Lauer (Director of Energy and the Environment), and Anil Pahwa (Professor of Electrical and Computer Engineering) are with Kansas State University, Manhattan, Kansas. 